\title{
Bedside ultrasound training using web-based e-learning and simulation early in the curriculum of residents
}

\author{
Yanick Beaulieu ${ }^{1}$, Réjean Laprise ${ }^{2}$, Pierre Drolet ${ }^{2}$, Robert L Thivierge ${ }^{2}$, Karim Serri $^{1}$, Martin Albert ${ }^{1,3}$,

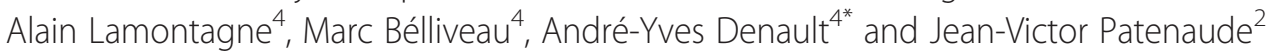

\begin{abstract}
Background: Focused bedside ultrasound is rapidly becoming a standard of care to decrease the risks of complications related to invasive procedures. The purpose of this study was to assess whether adding to the curriculum of junior residents an educational intervention combining web-based e-learning and hands-on training would improve the residents' proficiency in different clinical applications of bedside ultrasound as compared to using the traditional apprenticeship teaching method alone.

Methods: Junior residents $(n=39)$ were provided with two educational interventions (vascular and pleural ultrasound). Each intervention consisted of a combination of web-based e-learning and bedside hands-on training. Senior residents $(n=15)$ were the traditionally trained group and were not provided with the educational interventions.

Results: After the educational intervention, performance of the junior residents on the practical tests was superior to that of the senior residents. This was true for the vascular assessment $(94 \% \pm 5 \%$ vs. $68 \% \pm 15 \%$, unpaired student $t$ test: $p<0.0001$, mean difference: 26 (95\% Cl: 20 to 31)) and even more significant for the pleural assessment (92\% $\pm 9 \%$ vs. $57 \% \pm 25 \%$, unpaired student $t$ test: $p<0.0001$, mean difference: 35 (95\% Cl: 23 to 44)). The junior residents also had a significantly higher success rate in performing ultrasound-guided needle insertion compared to the senior residents for both the transverse ( $95 \%$ vs. $60 \%$, Fisher's exact test $p=0.0048)$ and longitudinal views (100\% vs. $73 \%$, Fisher's exact test $p=0.0055)$.

Conclusions: Our study demonstrated that a structured curriculum combining web-based education, hands-on training, and simulation integrated early in the training of the junior residents can lead to better proficiency in performing ultrasound-guided techniques compared to the traditional apprenticeship model.
\end{abstract}

Keywords: Ultrasound; Education; Residents; e-learning; Simulation; Safety

\section{Background}

The use of ultrasound has great potential to immediately provide diagnostic information at the bedside not assessable by physical examination alone. In recent years, there has been an explosion in the number of publications supporting the use of bedside ultrasound in both acute and non-acute care settings [1-3]. Results have shown that its use can speed up and improve the management of a variety of patient conditions and can serve

\footnotetext{
*Correspondence: andre.denault@umontreal.ca

${ }^{4}$ Faculty of Medicine, Department of Anesthesia, Montreal Heart Institute, Université de Montréal, 5000 Bélanger, Montréal H1T 1C8, Canada Full list of author information is available at the end of the article
}

as an invaluable tool for numerous clinical specialties including critical care, emergency medicine, internal medicine, anesthesiology, trauma, and many other disciplines [4-6]. Its use has also been shown to bring frequent changes in diagnosis and subsequent changes in therapy, often resulting in significant improvement in patient care and outcome [7]. But its successful application depends in most part on the user's skills and is operatordependent and therein lays one of the greatest challenges faced by clinicians in widely adopting bedside ultrasound. The demand for training is high but all too often, inadequate training programs are in place, if any at all.

\section{空}


The traditional medical education model which uses an apprenticeship approach to clinical learning may need to be re-assessed and augmented with additional training. A competency-based training model may be an important adjuvant to increase clinical skills. Competencybased training can be achieved using simulation, webbased learning tools, and formal hands-on training to allow a clinical procedure to be learned based on a system of standard metrics so that progress and proficiency can be recorded, followed, and assessed [8-11].

An adequate, focused assessment of the vessels and pleural space requires a thorough understanding of ultrasound principles, anatomy, pitfalls, and good interpretation and image acquisition skills. Targeted needle placement under ultrasound guidance requires specific psychomotor skills as well as hand-eye coordination.

The purpose of this study was to assess whether adding to the curriculum of the junior internal medicine residents an educational intervention combining webbased e-learning and hands-on training using human models and simulators would improve the residents' proficiency in different clinical applications of bedside ultrasound.

\section{Methods}

\section{Study design}

A prospective longitudinal cohort study was used to compare outcomes achieved at specific milestones along the residency program by an intervention and a control group.

\section{Participants}

All residents who started residency in internal medicine at the University of Montreal in July 2008 or after and were still registered as residents at the time of recruitment in the study were eligible to participate. To be included, they had to sign the consent form and agree to study participation requirements. They were excluded if they had studied another profession that uses ultrasound technology (e.g., radiology technician) before entering the residency program.

\section{Intervention}

The participants were trained on the use of bedside ultrasound either using a formal course in addition to the traditional apprenticeship teaching method (intervention group) or using the latter alone (control group).

The course used a combination of self-directed e-learning for acquisition of cognitive knowledge and a series of practical sessions for clinical skills.

Self-directed learning was facilitated using an interactive learning management system (LMS), developed by CAE Healthcare (Montreal, Canada) in collaboration with the Department of Medicine of the University of
Montreal. Since 2011, it has been adopted by the American College of Chest Physician (ACCP). It is part of the four mandatory courses leading to the Critical Care Ultrasonography certification. http://www.chestnet.org/ Education/Advanced-Clinical-Training/Certificate-ofCompletion-Program/Critical-Care-Ultrasonography.

This LMS provided descriptions of concepts and clinical applications using multimedia methods such as images, videos, and 3D animations. For each clinical application of bedside ultrasound, the curriculum was divided into one to three individual courses, each one including many modules (Figure 1). In each module, learners assessed their knowledge and learning by completing pre- and post-tests. An average of 10 to $12 \mathrm{~h}$ is required to complete the modules (Table 1 ). Practical sessions (60 to $90 \mathrm{~min}$ ) consisted of hands-on scanning and clinical teaching at bedside. They were provided by experienced clinical teachers to small groups of participants in various university-affiliated hospitals. Clinical skills were taught using volunteers (sick and healthy) and ultrasound phantoms. During practical sessions, teachers demonstrated how to scan the main vessels and reviewed anatomy, orientation, and pitfalls and how to perform ultrasound-guided needle insertion in various planes. In order to ensure training standardization, clinical teachers were provided with a checklist of items to be covered during each session. Checklists were

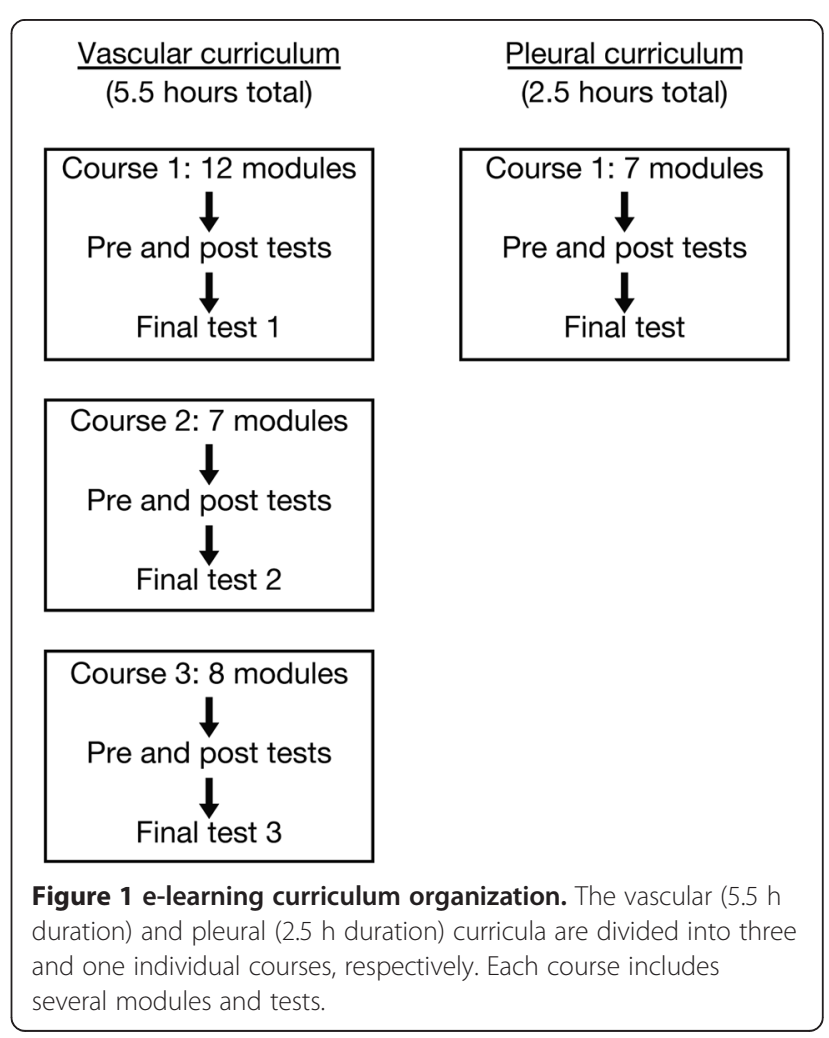


Table 1 Summary of the two educational interventions provided to the junior residents group

\begin{tabular}{|c|c|c|}
\hline Topic & Assessment of central and peripheral vessels & Assessment of pleural space and lung \\
\hline \multirow[t]{4}{*}{ Cognitive knowledge } & Understand basic physical properties of ultrasound & $\begin{array}{l}\text { Appreciate general indications for pleural ultrasound and the } \\
\text { literature pertinent to it }\end{array}$ \\
\hline & $\begin{array}{l}\text { Appreciate the literature pertinent to ultrasound-guided } \\
\text { vascular access }\end{array}$ & $\begin{array}{l}\text { Understand the general principles of ultrasound examination } \\
\text { of the pleural space }\end{array}$ \\
\hline & $\begin{array}{l}\text { Recognize the criteria for difficult venous access and } \\
\text { indications for ultrasound-guided line placement }\end{array}$ & \\
\hline & $\begin{array}{l}\text { Learn the general principles of ultrasound examination } \\
\text { of vessels }\end{array}$ & \\
\hline Psychomotor skills & $\begin{array}{l}\text { Demonstrate how to perform an ultrasonographic } \\
\text { examination of the main vessels in the transverse } \\
\text { and longitudinal planes: internal jugular/subclavian/ } \\
\text { femoral/peripheral vein }\end{array}$ & $\begin{array}{l}\text { Demonstrate how to perform an ultrasonographic examination } \\
\text { of the pleural space and lung }\end{array}$ \\
\hline Attitudes & $\begin{array}{l}\text { Know how to properly interpret and report the } \\
\text { ultrasound assessment of vessels and the } \\
\text { ultrasound-guided vascular cannulation procedure. }\end{array}$ & $\begin{array}{l}\text { Know how to properly interpret and report the ultrasound } \\
\text { assessment of the pleural space and lung and the } \\
\text { ultrasound-guided thoracentesis procedure }\end{array}$ \\
\hline Self-directed e-learning & $5.5 \mathrm{~h}$ & $2.5 \mathrm{~h}$ \\
\hline Hands-on sessions & $5.0 \mathrm{~h}$ & $2.0 \mathrm{~h}$ \\
\hline Duration & 6 weeks & 2 weeks \\
\hline
\end{tabular}

provided in advance to the participants in order to set expectations and ensure optimal preparation.

\section{Study objectives}

The study objective is to assess whether adding to the curriculum of the junior internal medicine residents an educational intervention combining self-directed learning and hands-on training improved residents' competency in different clinical applications of bedside ultrasound as compared to using the traditional apprenticeship teaching method alone.

\section{Outcome and variables}

We used knowledge, skills, and self-confidence as primary endpoints of participants' competency.

Knowledge was measured as the percentage of accurate responses that the participants provided on a series of comprehensive tests linked to the overall learning objectives of the course. This outcome was assessed using the final tests already integrated in the LMS (Figure 1). These tests were developed based on published guidelines on bedside ultrasound from international expert panel $[1,4]$.

Skills were assessed as the percentage of either accurate responses to questions or well-executed tasks that the participants were requested to perform during practical and oral examinations. Content was based on current guidelines describing clinical knowledge and skills required for bedside ultrasonography [1,4].

An important aspect of the ultrasound assessment is the component related to the guidance of a needle in a specific vessel under direct vision and in real time. This skill was assessed using ultrasound phantoms, both for transverse and longitudinal views, and measured as the success of the guided procedure and the occurrence of posterior wall perforation.

Self-confidence with regard to using bedside ultrasound with real patients was measured on a 5-point Likert scale using a standard question already validated in the literature [12]: In your future rotations/clinical calls, how confident are you, on a scale of 1 (not at all confident) to 5 (extremely confident), to independently carry out on real patients the tasks reviewed in this examination?

The participating residents' socio-demographic characteristics (age, gender, medical school of graduation) and previous exposure to bedside ultrasound were assessed using a self-reported questionnaire.

\section{Implementation}

A convenience sample of residents was assembled after protocol approval by the University of Montreal's Institutional Review Board (CPER-11-034-D). The internal medicine residency program registration records of the Faculty of Medicine were used to identify the eligible residents. An invitation letter was sent by e-mail to all eligible residents, explaining briefly the project goal and describing in detail the participation requirements and the different aspects of confidentiality, along with the consent form and an invitation to call the study coordinator if they needed more detailed information on the study requirements.

Consenting residents who started residency in 2010 (hereafter referred to as junior residents) were assigned to the intervention cohort whereas those who started in the previous 2 years were assigned to the control cohort 
(senior residents). The residents of the intervention cohort were further assigned to the specific clinical teachers that were responsible to carry out the intervention in their clinical setting, i.e., in one of the university-affiliated hospitals. In larger hospitals, the project coordinator randomly allocated the residents between teachers in order to obtain small groups of no more than seven residents.

Clinical teachers were chosen according to the following criteria: recognized expertise in bedside ultrasound and affiliation to the University of Montreal. Since access to LMS data was an integral part of their teaching role, they were aware of test results for the junior residents that were assigned to their own group. However, they were blinded as to which residents had consented to the study, and they did not have access to other data such as those collected by self-report questionnaires nor to any data pertaining to other residents.

As part of their mandatory training, the junior residents were provided with two educational interventions, each covering different areas of bedside ultrasound (assessment of central and peripheral vessels and assessment of pleural space and lung; Table 1). At the onset of the study, the senior residents had had 2 to 3 years of variable clinical exposure to bedside ultrasound and had learned their skills based on the traditional apprenticeship model. The traditional apprenticeship model consists of bedside supervision by the senior residents, critical care fellow, and critical care attendings. Informal courses were provided depending on the critical care staffing interest and expertise. After recruitment in the study, they were not provided with the educational interventions but continued training as usual.

The socio-demographic and previous exposure questionnaire was administered by e-mail at recruitment time and collected by the study coordinator. Knowledge tests were administered online at the end of each intervention, and the participants' answers were automatically compiled by the LMS software. Skills were measured at baseline for the intervention group and at the end of each intervention for both groups. Practical examinations were administered individually by clinical teachers who were provided with objective assessment criteria and detailed instructions. The six examiners who were used in the intervention group were the same clinical teachers who participated to the study but did not assess their own students. The four examiners used for the control group were not involved in the study. Selfconfidence questionnaires were administered following practical skill assessments.

\section{Statistics}

A series of hypotheses were tested by comparing the level of knowledge, skills, and confidence achieved by the participants of the intervention and control cohorts at specific milestones along the residency program, as per protocol. Analyses were conducted with Prism 5.0 (GraphPad Software, La Jolla, CA, USA). Continuous variables were compared with either the Student's $t$ test or the one-way ANOVA followed, when appropriate, with Tukey's post-tests. Fisher, chi-square, and chi-square for trends tests were used for categorical variables, and Bonferroni correction was applied for multiple comparisons involving the same subset of data. A $p$ value $<0.05$ was considered significant.

\section{Results}

Participant recruitment took place between March 2011 and April 2011, and the study was conducted between May 2011 and September 2011. The participants came from five different hospitals. Thirty-seven junior residents (23 females/14 males: usual gender distribution at the University of Montreal) and 15 seniors ( 7 females/8 males) went through the different steps of the study. All eligible junior residents from the 2010 internal medicine cohort were recruited. The junior residents were assigned to six clinical teachers according to protocol. The 15 senior residents were recruited on a voluntary basis out of the 70 residents of the 2008 and 2009 internal medicine cohorts.

For the vascular curriculum, the junior residents obtained higher scores than the senior residents on the three knowledge tests $(85 \% \pm 6 \%$ vs. $67 \% \pm 14 \%, p<0.0001$; $95 \% \pm 7 \%$ vs. $77 \% \pm 15 \%, p<0.0001 ; 94 \% \pm 8 \%$ vs. $74 \% \pm$ $8 \%, p<0.0001)$. Their results were also higher in the case of the pleural and lung curriculum $(92 \% \pm 4 \%$ vs. $74 \% \pm$ $12 \%, p<0.0001$ ) (Figure 2).

The scores of the junior residents on the practical vascular test significantly improved after the educational intervention $(45 \% \pm 20 \%$ vs. $94 \% \pm 5 \%, p<0.001)$ (Figure 3). The results on the pleural practical test were also

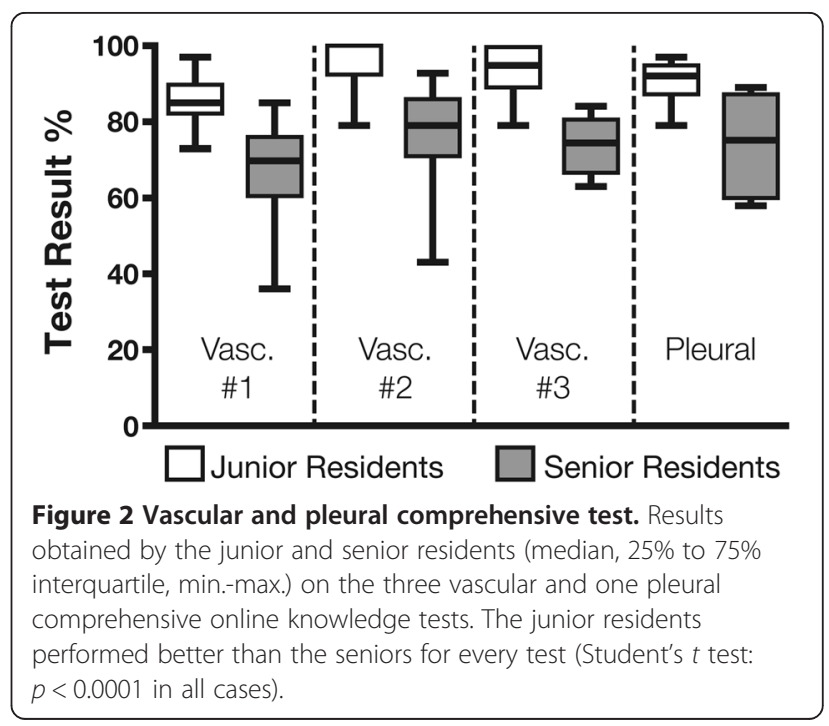




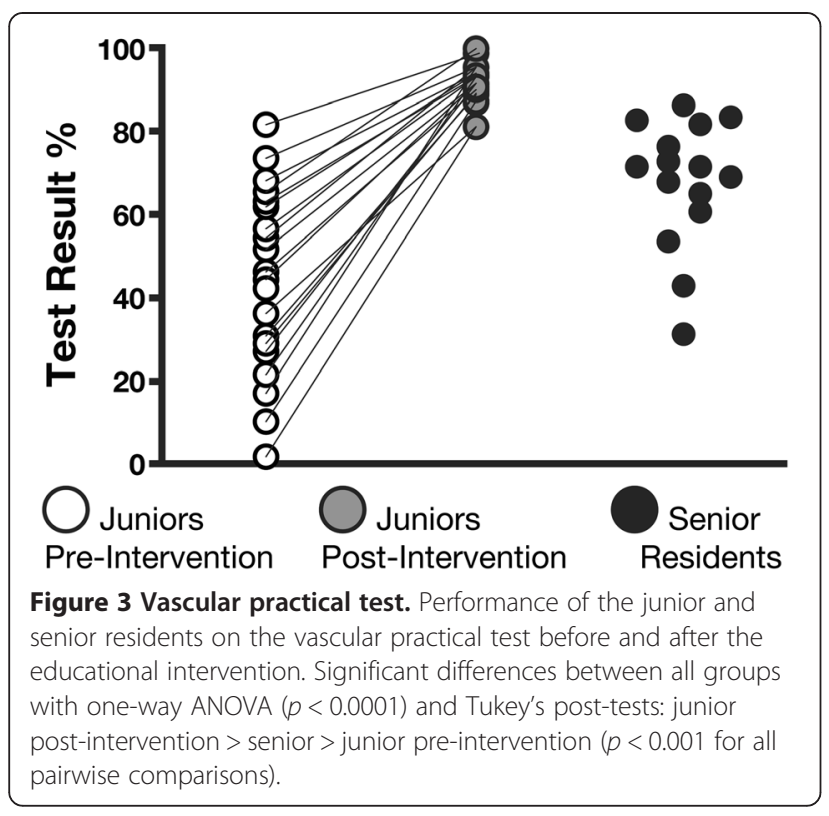

improved by the intervention $(44 \% \pm 18 \%$ vs. $92 \% \pm 9 \%$, $p<0.001$ ) (Figure 4).

The results of the senior residents on the vascular $(68 \% \pm 15 \%)$ and pleural $(57 \% \pm 25 \%)$ practical tests were lower than those of the junior residents after the educational intervention $(p<0.001$ in both cases) (Figures 3 and 4).

Before the educational intervention, the success rate of the junior residents in adequately guiding the needle in the vessel was $44 \%$ and $56 \%$ in the transverse and longitudinal views, respectively (Table 2). In the post-educational intervention assessment, these rates increased significantly

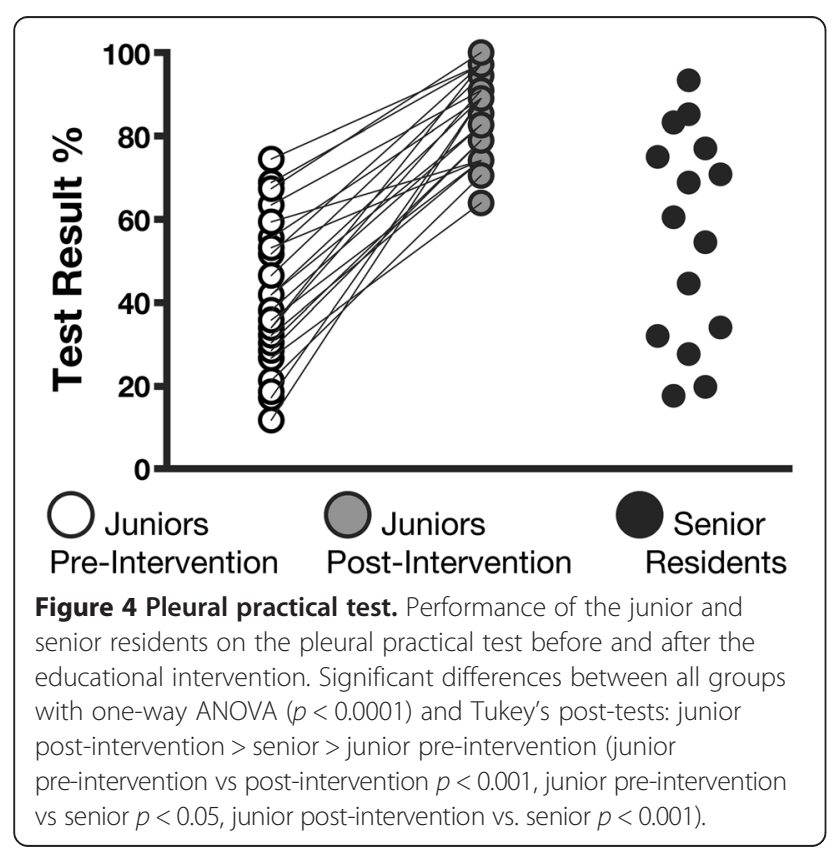

to $95 \%(p<0.0002)$ and $100 \%(p<0.0002)$, respectively. The success rate of the senior residents in both transverse $(60 \%)$ and longitudinal view (73\%) was inferior compared to the results of juniors who benefited from the educational intervention (transverse $p=0.0096$, longitudinal $p=0.0105$ ) (Table 2).

Before the educational intervention, the rate of perforation of the posterior wall of the vein was $64 \%$ and $47 \%$ in the transverse and longitudinal views, respectively, for the junior residents. In the post-educational intervention period, these rates decreased to $16 \%(p<0.0002)$ and $14 \%(p=0.0154)$, respectively. The rates of perforation of the vein's posterior wall by the senior residents were $27 \%$ and $43 \%$ in the transverse and longitudinal views, respectively. These results were not significantly different from the results of the juniors who were exposed to the educational intervention (Table 2).

Significant structures were correctly identified more frequently during the pleural space and lung examination by the junior residents following the educational intervention. It was the case for the ribs (pre- vs. postintervention: $61 \%$ vs. $97 \%, p=0.0002$ ), the diaphragm (37\% vs. $97 \%, p<0.0001$ ), the visceral and parietal pleura (31\% vs. $91 \%, p<0.0001)$, the normal/consolidated/ atelectatic lung ( $28 \%$ vs. $74 \%, p=0.0001$ ), and the presence of pleural effusion ( $44 \%$ vs. $80 \%, p=0.0031)$.

The baseline scores of the junior residents on the practical tests in relationship to the hospital in which they were based were different. We found significant variability for the practical pre-intervention vascular exam (Figure 5). There was no difference between trainees after the intervention in relationship to their affiliated hospital. There was no significant difference either in the results of the comprehensive online vascular or pleural knowledge tests in relationship to the various hospitals in which the residents were based.

No significant relationships were found between the various test scores, gender, and clinical teachers.

Self-confidence was significantly higher amongst the junior residents who completed the educational training than amongst the senior residents $(p=0.0093)$. A total of $45 \%$ of the junior residents felt either very or totally confident regarding their ability to perform adequate ultrasound examination compared to $33 \%$ of the seniors.

\section{Discussion}

Our study demonstrated that a structured curriculum combining web-based education, hands-on training, and simulation integrated early in the training of the junior residents can lead to better proficiency in performing ultrasound-guided techniques compared to the traditional apprenticeship model.

Some of the very important factors to bedside ultrasound training are to create a valid and standardized 
Table 2 Rates for correct needle placement into the vein and accidental perforation of the posterior wall

\begin{tabular}{llll}
\hline & $\begin{array}{l}\text { Junior residents pre-intervention } \\
(\boldsymbol{n}=\mathbf{3 7 )}\end{array}$ & $\begin{array}{l}\text { Junior residents post-intervention } \\
(\boldsymbol{n}=\mathbf{3 7})\end{array}$ & $\begin{array}{l}\text { Senior residents } \\
(\boldsymbol{n}=\mathbf{1 5})\end{array}$ \\
\hline View & & Transverse - longitudinal \\
Success rate in guiding the needle into the vein & $44 \%^{*}$ to $56 \%^{*}$ & $95 \%$ to $100 \%$ & $60 \% \%^{* *}$ to $73 \%^{* * *}$ \\
Perforation of the posterior wall of the vein & $64 \%^{*}$ to $47 \%^{* * * *}$ & $16 \%$ to $14 \%$ & $27 \%$ to $43 \%$ \\
\hline
\end{tabular}

During practical vascular examination. ${ }^{*} p<0.0002,{ }^{* *} p=0.0096,{ }^{* * *} p=0.0105,{ }^{* * * *} p=0.0154$ vs. junior residents post-intervention (Fisher's exact test with Bonferroni's correction for two comparisons).

training model, ensure that effective learning can occur, and create performance metrics that can accurately test a student's proficiency that ultimately measures learning [13-15].

When risk is dependent on the level of training, peril is imposed by a traditional training paradigm that involves practicing on patients [8,16-19]. Studies have shown the higher complication rates associated with relative lack of experience in central venous catheter placement [20-23].

Simulation-based education has been used to provide opportunities for safe and deliberate practice, shape the acquisition of clinical skills, and improve patient care and outcomes [10]. Analysis of our results shows a significant improvement in the overall proficiency of the junior residents in performing bedside ultrasound when comparing the pre- and post-educational periods for both the vascular and the pleural space assessment. This improvement occurred over a relatively short period of time of a few months. Also, we have shown a significant improvement in the success rate of the actual ultrasound guidance of the needle in a vessel in both the transverse and longitudinal views when comparing the pre- and post-educational periods. In terms of safety, we have shown that complications related to vascular access using ultrasound-assisted guidance can be reduced as there were fewer posterior wall penetration in the junior

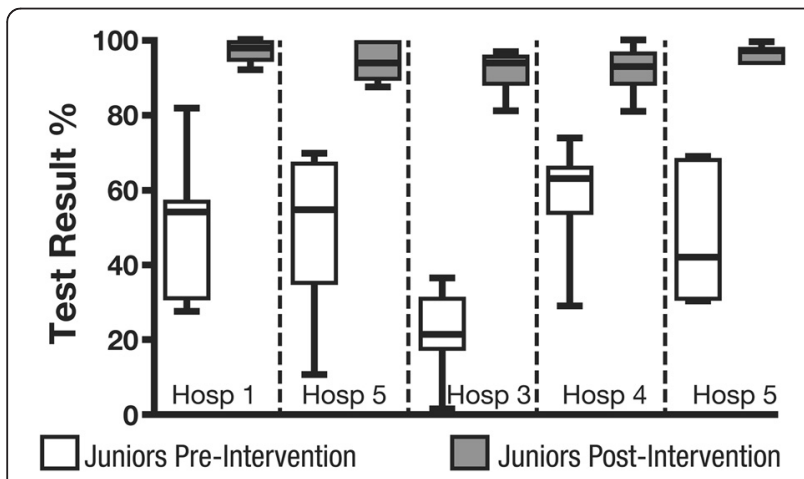

Figure $\mathbf{5}$ Educational intervention. Performance of the junior residents pre- and post-educational intervention (median, 25\% to $75 \%$ interquartile, min.-max.) in relationship to their source hospital. Pre-intervention scores from hospital 3 were significantly lower (one-way ANOVA $p=0.006)$ than scores from hospitals $1(p<0.05)$, $2(p<0.05)$, and 4 ( $p<0.001)$ (Tukey's post-tests). resident group after the educational intervention. Posterior wall penetration can be associated with carotid puncture and if too deep other complications such as pneumothorax.

These findings demonstrate the efficacy of the educational intervention in rapidly bringing the junior residents to an adequate level of proficiency by using a blended learning approach. The junior residents enrolled in this study received the educational intervention at the end of their first year - beginning of their second year of residency. It is typically at that time that the residents start doing rotation and taking calls in the intensive care units during which they will often need to proceed with central line insertion and thoracentesis.

From a medical and patient care perspective, improved patient safety is probably one of the most important benefits of having an efficient training program such as the one we have described. Evidence has shown that simulation-based, structured training can not only lead to better proficiency in performing the technique compared to the traditional apprenticeship model but that this better proficiency can also translate into better clinical outcomes. A study by Barsuk et al. [10] who assessed the effect of a simulation-based mastery learning model on central venous catheter insertion skill and the prevalence of procedure-related complications in a medical intensive care unit over a 1-year period showed that the simulation-trained residents had a much higher success rate and fewer needle passes when compared to the traditionally trained residents. More importantly, they showed a dramatic reduction in arterial puncture $(1 \%$ vs. $14 \%, p<0.0005)$ in the simulator-trained group. Another study by Sekiguchi et al. [23] showed a decrease in complications from central line placement in a group of the junior residents who received a structured, pre-rotational training on ultrasound-guided central line placement when compared with previous groups who did not received structured educational training. Placement failure rate decreased from $22.8 \%$ to $16.2 \%(p=0.02)$, and arterial punctures decreased from $4.2 \%$ to $1.5 \%(p=0.03)$.

A study by Cohen et al. [24] demonstrated convincingly that simulation-based education in central venous catheter insertion was a cost-effective intervention that directly benefited patients. Specific patient benefits included fewer 
catheter-related bloodstream infections and decreased length of medical intensive care unit and hospital stays. The simulation-based intervention resulted in saving of more than $\$ 800,000,137$ patient hospital days, and around 120 medical intensive care unit days [24]. These studies support the evidence that simulation-based process improvement mechanisms can enhance patient safety and quality of care.

Our standardized blended learning approach using e-learning, hands-on, and simulation offers two important benefits when applied with adequate rigor: (1) it provides a risk-free training environment and (2) it accelerates the learning curve and allows introduction of the procedures on real patients at a safer level of performance. As demonstrated in our study, despite being 1 to 2 years more junior in terms of academic experience and clinical exposure, in the post-educational period, the junior residents were more proficient than the senior residents at performing the overall bedside ultrasound assessment of vessel and pleural space with higher success rate of guided-needle insertion, lower rate of posterior wall perforation, and higher success in identifying the key anatomic landmarks when performing the pleural exam. Although the better scores on both the knowledge and practical tests do not imply the ability to perform the procedure independently, it provides a metric by which educators can ensure a minimum level of proficiency before allowing trainees to perform such procedures on patients under supervision [20]. This reflects a necessary first step in promoting patient safety.

Our educational intervention provides a way to accelerate the learning curve so that it introduces a safer level of performance earlier in the clinical training of the residents.

\section{Potential limitations}

The fact that enrolment of the senior residents was on a voluntary basis could have introduced a form of selection bias in the study as those enrolling themselves in the study might have been those individuals that were more comfortable with bedside ultrasound. This potential bias would potentially reduce the effect of the educational intervention. Despite this, the impact of the educational intervention remained significant. The junior residents performed the practical tests before the educational interventions and after the intervention. One could argue that the junior residents knew what would be asked in the practical test after their training and that this could lead to a better performance. However, the practical tests were very rigorous and geared towards assessing proficiency of the resident in a variety of skills. The various skills tested were rated as being successfully performed only if the examiner felt that the resident had a solid understanding of what was demonstrated. Also, as there were more than 16 weeks separating the initial practical test and the final practical test, it is not likely that the junior residents remembered the questions that were initially asked. Several studies have also shown the benefit of e-learning. Cuca et al. compared traditional versus the e-learning of 75 medical students of a lung ultrasound training program [25]. There were no differences between the groups in terms of retention. Platz et al. studies physicians from two German emergency departments who were randomized into a classroom group with traditional lectures and a web group who watched narrated lectures online [26]. All participants completed a preand post-test and a second post-test 8 weeks later. Both the classroom and web group showed significant improvement in pre- and post-test scores with no differences in terms of retention at 8 weeks. Finally, another study by Blackstock et al. evaluated sonographic knowledge in 45 medical students using web-based tutorials. They found similar results compared to an emergency medicine resident [27]. The major difference between these studies and ours is that both theoretical knowledge and clinical skills were also assessed in terms of vascular access and pleural examination.

\section{Conclusions}

Our study demonstrated that a structured curriculum combining web-based education, hands-on training, and simulation can lead to better proficiency in performing ultrasound-guided techniques compared to the traditional apprenticeship model. Future studies are necessary to demonstrate that this better proficiency will translate into better clinical outcomes and overall improved patient care.

\section{Competing interests}

The authors declare that they have no competing interests.

\section{Authors' contributions}

All the authors have contributed to the study in terms of conception, design, analysis, and interpretation of data. They all have reviewed the manuscript and have given final approval of the version to be published.

\section{Acknowledgements}

The work was performed in the following institutions: Sacre-Coeur Hospital, Montreal, Quebec, Canada, CHUM (Centre Hospitalier Universitaire de Montreal), Montreal, Quebec, Canada, Maisonneuve-Rosemont Hospital, Montreal, Quebec, Canada and the Centre d'Apprentissage des Attitudes et Habiletés Cliniques (CAAHC), Université de Montréal, Montreal, Quebec, Canada.

The authors would like to thank Antoinette Paolitto of the Montreal Heart Institute Research Center.

\section{Funding}

This study was funded by an unrestricted grant from Université de Montréal Centre d'Apprentissage des Attitudes et Habiletés Cliniques (CAAHC) and from CAE Healthcare.

Université de Montréal Centre d'Apprentissage des Attitudes et Habiletés Cliniques (CAAHC) provided the simulation center facilities for examinations of the senior residents.

CAE Healthcare provided the e-learning access for the junior residents and paid the salary of a research assistant for the duration of the study. Other than for those two contributions, CAE healthcare was not involved in any aspects of the study design or results. 


\section{Author details}

${ }^{1}$ Faculty of Medicine, Department of Medicine and Hôpital Sacré-Coeur, 5400 boul. Gouin ouest, Montréal H4J 1C5, Canada. ²Faculty of Medicine, Department of Medicine and Centre d'Apprentissage des Attitudes et Habiletés Cliniques (CAAHC), Université de Montréal, 2900 boul. Edouard-Montpetit, Montréal H3T 1J4, Canada. ${ }^{3}$ Research Centre, Hôpital Sacré-Coeur, 5400 boul. Gouin ouest, Montréal H4J 1C5, Canada. ${ }^{4}$ Faculty of Medicine, Department of Anesthesia, Montreal Heart Institute, Université de Montréal, 5000 Bélanger, Montréal H1T 1C8, Canada.

Received: 17 September 2014 Accepted: 23 December 2014

Published online: 21 January 2015

\section{References}

1. Mayo PH, Beaulieu Y, Doelken P, Feller-Kopman D, Harrod C, Kaplan A, Oropello J, Vieillard-Baron A, Axler O, Lichtenstein D, Maury E, Slama M, Vignon P (2009) American College of Chest Physicians/La Societe de Reanimation de Langue Francaise statement on competence in critical care ultrasonography. Chest 135(4):1050-1060

2. Blaivas M, Kirkpatrick A, Sustic A (2007) Future directions and conclusions. Crit Care Med 35(5 Suppl):S305-S307

3. Chalumeau-Lemoine L, Baudel JL, Das V, Arrive L, Noblinski B, Guidet B, Offenstadt G, Maury E (2009) Results of short-term training of naïve physicians in focused general ultrasonography in an intensive-care unit. Intensive Care Med 35(10):1767-1771

4. Cholley BP, Mayo PH, Poelaert J, Vieillard-Baron A, Vignon P, Alhamid S, Balik M, Beaulieu Y, Breitkreutz R, Canivet JL, Doelken P (2011) International expert statement on training standards for critical care ultrasonography. Intensive Care Med 37(7):1077-1083

5. Huang SJ, McLean AS (2010) Do we need a critical care ultrasound certification program? Implications from an Australian medical-legal perspective. Crit Care 14(3):313

6. Beaulieu Y, Marik PE (2005) Bedside ultrasonography in the ICU: part 1. Chest 128(2):881-895

7. Kanji HD, McCallum J, Sirounis D, MacRedmond R, Moss R, Boyd JH (2014) Limited echocardiography-guided therapy in subacute shock is associated with change in management and improved outcomes. J Crit Care 29(5):700-705

8. Dong Y, Suri HS, Cook DA, Kashani KB, Mullon JJ, Enders FT, Rubin O, Ziv A, Dunn WF (2010) Simulation-based objective assessment discerns clinical proficiency in central line placement: a construct validation. Chest 137 (5):1050-1056

9. Mendiratta-Lala M, Williams T, de Quadros N, Bonnett J, Mendiratta V (2010) The use of a simulation center to improve resident proficiency in performing ultrasound-guided procedures. Acad Radiol 17(4):535-540

10. Barsuk JH, McGaghie WC, Cohen ER, O'Leary KJ, Wayne DB (2009) Simulation-based mastery learning reduces complications during central venous catheter insertion in a medical intensive care unit. Crit Care Med 37(10):2697-2701

11. Wahidi MM, Silvestri GA, Coakley RD, Ferguson JS, Shepherd RW, Moses L, Conforti J, Que LG, Anstrom KJ, McGuire F, Colt H, Downie GH (2010) A prospective multicenter study of competency metrics and educational interventions in the learning of bronchoscopy among new pulmonary fellows. Chest 137(5):1040-1049

12. Likert R (1931) A technique for the measurement of attitudes. Arch Psycol 140:1-55

13. Gallagher AG, Satava RM (2002) Virtual reality as a metric for the assessment of laparoscopic psychomotor skills. Learning curves and reliability measures. Surg Endosc 16(12):1746-1752

14. Towbin AJ, Paterson BE, Chang PJ (2008) Computer-based simulator for radiology: an educational tool. Radiographics 28(1):309-316

15. Davis D, Bordage G, Moores LK, Bennett N, Marinopoulos SS, Mazmanian PE, Dorman T, McCrory D (2009) The science of continuing medical education: terms, tools, and gaps: effectiveness of continuing medical education: American College of Chest Physicians Evidence-Based Educational Guidelines. Chest 135(3 Suppl):8S-16S

16. National Institute for Clinical Excellence (2002) Guideline on the use of ultrasound location devices for placing central venous catheters. NICE Technol Appraisal Guide 49:1-55

17. Mayo PH, Goltz HR, Tafreshi M, Doelken P (2004) Safety of ultrasoundguided thoracentesis in patients receiving mechanical ventilation. Chest 125(3):1059-1062
18. Nazeer SR, Dewbre H, Miller AH (2005) Ultrasound-assisted paracentesis performed by emergency physicians vs the traditional technique: a prospective, randomized study. Am J Emerg Med 23(3):363-367

19. Mallory DL, McGee WT, Shawker TH, Brenner M, Bailey KR, Evans RG, Parker MM, Farmer JC, Parillo JE (1990) Ultrasound guidance improves the success rate of internal jugular vein cannulation. A prospective, randomized trial. Chest 98(1):157-160

20. Murin S, Stollenwerk NS (2010) Simulation in procedural training: at the tipping point. Chest 137(5):1009-1011

21. Karakitsos D, Labropoulos N, De GE, Patrianakos AP, Kouraklis G, Poularas J Samonis G, Tsoutsos DA, Konstadoulakis MM, Karabinis A (2006) Real-time ultrasound-guided catheterisation of the internal jugular vein: a prospective comparison with the landmark technique in critical care patients. Crit Care 10(6):R162

22. Leung J, Duffy M, Finckh A (2006) Real-time ultrasonographically-guided internal jugular vein catheterization in the emergency department increases success rates and reduces complications: a randomized, prospective study. Ann Emerg Med 48(5):540-547

23. Sekiguchi H, Tokita JE, Minami T, Eisen LA, Mayo PH, Narasimhan M (2011) A prerotational, simulation-based workshop improves the safety of central venous catheter insertion: results of a successful internal medicine house staff training program. Chest 140(3):652-658

24. Cohen ER, Feinglass J, Barsuk JH, Barnard C, O'Donnell A, McGaghie WC, Wayne DB (2010) Cost savings from reduced catheter-related bloodstream infection after simulation-based education for residents in a medical intensive care unit. Simul Healthc 5(2):98-102

25. Cuca C, Scheiermann P, Hempel D, Via G, Seibel A, Barth M, Hirche TO, Walcher F, Breitkreutz R (2013) Assessment of a new e-learning system on thorax, trachea, and lung ultrasound. Emerg Med Int 2013:145361

26. Platz E, Goldflam K, Mennicke M, Parisini E, Christ M, Hohenstein C (2010) Comparison of Web-versus classroom-based basic ultrasonographic and EFAST training in 2 European hospitals. Ann Emerg Med 56(6):660-667

27. Blackstock U, Munson J, Szyld D (2014) Bedside ultrasound curriculum for medical students: Report of a blended learning curriculum implementation and validation. J Clin Ultrasound. Aug 14. doi:10.1002/jcu.22224. [Epub ahead of print].

\section{Submit your manuscript to a SpringerOpen ${ }^{\odot}$ journal and benefit from:}

- Convenient online submission

- Rigorous peer review

- Immediate publication on acceptance

- Open access: articles freely available online

- High visibility within the field

- Retaining the copyright to your article

Submit your next manuscript at springeropen.com 